\title{
Effects of Physiotherapeutic Interventions on Quality of Life and Respiratory Function of subjects with COPD
}

\author{
Danilo de Macêdo Moura', Suenny Marrocos de Lima Moura', Alessandra Feitosa Gonçalves', \\ Maria Alessandra Sipriano da Silva', Georgia Freire Paiva Winkeler², Simone dos Santos Maciel², \\ Clarice Maria de Lucena Martins ${ }^{4}$, Heleodório Honorato dos Santos ${ }^{3,4}$
}

\begin{abstract}
Background: Chronic Obstructive Pulmonary Disease (COPD) treatment includes a multidisciplinary approach, with physiotherapy a prominent role that promotes a positive impact on the quality of life (QOL) of these patients. Objective: To analyze the effects of physiotherapeutic interventions on QOL, lung volumes and capacities, and respiratory muscle strength in COPD patients. Methods: 17 subjects participated in the study, randomly divided into 2 groups: 1 ) Maneuvers: $62.7 \pm 15.4$ years, $1.65 \pm 0.12 \mathrm{~m}$, $81.4 \pm 18.2 \mathrm{~kg}$, body Mass Index (BMI) $29.9 \pm 5.0 \mathrm{~kg} / \mathrm{m}^{2} ; 2$ ) Threshold: $64.4 \pm 11.2$ years, $1.58 \pm 0.08 \mathrm{~m}, 70.7 \pm 9.4 \mathrm{~kg}, \mathrm{BMI} 28.6 \pm 3.7 \mathrm{~kg} / \mathrm{m}^{2}$, with COPD, without neurological, musculoskeletal, cardiovascular or cognitive impairment, which made it impossible to participate in the physiotherapeutic intervention programs. QOL was analyzed using the Saint George Hospital questionnaire on Respiratory Disease (SGRQ); spirometry and respiratory muscle strength were analyzed by manovacuometry using a pneumotachograph. Data were analyzed in SPSS (20.0), Student's t-test (paired) and Wilcoxon test were used for pre and post-intervention comparison of the SGRQ domains and total score, Vital Capacity (VC), Forced Vital Capacity (FVC), Forced Expiratory Volume (FEV $)_{1}$, Maximal Inspiratory Pressure (MIP) and Maximal Expiratory Pressure (MEP); and Student's t-tests (independent) and Mann-Whitney were used in the intergroup comparison, all with a significance level of $5 \%$. Results: There was a significant difference in both groups $(P<0.05)$ in the pre- and post-intervention comparison of the three domains (Symptoms, Activities and Psychosocial Impact) and total SGRQ score, but this did not occur with spirometric variables. In the manovacuometry, the Wilcoxon test showed a significant difference in the pre and post-intervention values of MIP and MEP. Conclusion: Improved QOL and MIP and MEP muscle strength of all COPD patients was observed, regardless of the groups Maneuvers or Threshold.

This trial was registered under REBEC under number: RBR-4VGP58
\end{abstract}

Keywords: Respiratory Disease; Spirometry; Physiotherapy; Daily Activities; Quality of Life.

\section{INTRODUCTION}

Chronic Obstructive Pulmonary Disease (COPD) is considered a worldwide public health problem, characterized by chronic and progressive obstruction of the airflow, partially reversible, leading to high morbidity and mortality, especially in older adults ${ }^{(1,2)}$. In Brazil, there are about 7.5 million people afflicted with COPD, being considered the seventh cause of mortality with more than 37,000 deaths per year, bringing an annual public cost of approximately $R \$ 100$ million, as $70 \%$ of subjects depend on the Unified National Health System (SUS) for treatment ${ }^{(3)}$. Destruction of the pulmonary parenchyma caused by COPD causes loss of alveolar connections of the small airways and a decrease in pulmonary elasticity, making it difficult to open these pathways during expiration, leading to an increase in functional residual capacity (FRC) and a

decrease in inspiratory capacity (IC), resulting in pulmonary hyperinflation ${ }^{(4-6)}$ and reduced tolerance to physical exertion ${ }^{(7)}$. Pulmonary hyperinflation alters the shape and geometry of the thoracic wall, resulting in chronic reduction of the diaphragm apposition zone, decreasing the muscle's capacity to generate force, thereby increasing mechanical workload and airflow limitation, leading to weakness and a decrease in inspiratory muscle strength associated with reduced diaphragmatic yield ${ }^{(5,8)}$.

Spirometry is one of the best methods to measure changes in respiratory mechanics caused by COPD, and can be used in both the diagnosis and evaluation of pulmonary function. It is possible to obtain dynamic pulmonary volume values via spirometry ${ }^{(9)}$ which provide essential information for

Corresponding author: Heleodório Honorato dos Santos. Address: Av. Mons. Odilon Coutinho, 191/402, Cabo Branco, João Pessoa (PB), Brasil. CEP: $58045-120$.

Phone: 005583 99613-7900. E-mail: dorioufpb@gmail.com

${ }^{3}$ Departamento de Fisioterapia da Universidade Federal da Paraíba/UFPB João Pessoa, Paraíba, Brasil.

${ }^{4}$ Programa Associado de Pós-Graduação em Educação Física (PAPGEF) - UPE/UFPB, João Pessoa, Paraíba, Brasil.

Full list of author information is available at the end of the article.

Financial support: None. 
characterizing the pathophysiological state of the lungs ${ }^{(10)}$. As spirometry is defined as the measurement of volumes and airflows, especially Vital Capacity (VC), Forced Expiratory Volume in the first second $\left(\mathrm{FEV}_{1}\right)$ and Forced Vital Capacity (FVC), in addition to the correlations between these, its evaluation becomes essential in the diagnosis and treatment of individuals with airflow restriction ${ }^{(11,12)}$. Abnormal spirometry is an important prognosis in patients with COPD, since a progressive decrease in $\mathrm{FEV}_{1}$ is indicative of their survival. In addition, respiratory muscle weakness is related to VC, where a decrease of respiratory muscle determines a reduction of more than $50 \%$ of the normal force of these muscles ${ }^{(12)}$. In addition, manovacuometry is also an indispensable method to evaluate inspiratory muscle strength (maximum inspiratory pressure - MIP) and expiratory muscles (maximal expiratory pressure - MEP), being considered an important tool of respiratory physical therapy ${ }^{(13)}$. It is known today that minimizing complications resulting from pulmonary functional loss through respiratory exercises increases pulmonary ventilation and gas exchange efficiency, thus improving the contraction efficiency of respiratory muscles, reducing the sensation of dyspnea and energy expenditure during ventilation, and the individual can perform their activities of daily living ( $A D L$ ) without major disruption to the body ${ }^{(14-16)}$. Therefore, COPD treatment includes a multidisciplinary approach which takes into account aerobic and inspiratory muscle training, as well as behavioral instructions ${ }^{(14-17)}$, in addition to physiotherapy having a prominent role, since its treatment has a positive impact on the quality of life of these individuals ${ }^{(17)}$. Currently, there is consensus in the rehabilitation of these patients to improve aerobic capacity, which may be associated with other techniques such as respiratory muscle resistive training ${ }^{(18,19)}$, however, the lack of elucidation of these protocols ${ }^{(20)}$ and the few studies that specifically evaluate thoracic muscle changes ${ }^{(18)}$ make this study interesting. Based on this, it is hypothesized that there is improvement in respiratory muscle strength and lung function after the rehabilitation program, accompanied by an increase in the quality of life (QOL) of these patients. Thus, the objective of the present study was to compare the effects of two physiotherapeutic intervention programs on QOL, lung volumes and capacities, and respiratory muscle strength in COPD patients.

\section{METHODS}

\section{Sample characterization}

Initially, the sample consisted of 23 subjects; however, only 17 patients completed the study and were randomly divided into 2 groups (Maneuvers and Threshold). The "Maneuvers" group consisted of 7 patients $(5$ males and 2 females: $62.7 \pm 15.4$ years, $1.65 \pm 0.12 \mathrm{~m}, 81.4 \pm 18.2 \mathrm{~kg}$ and body mass index (BMI): $29.9 \pm 5.0 \mathrm{~kg} / \mathrm{m}^{2}$ ) and the "Threshold" group had 10 subjects ( 4 males and 6 females: $64.4 \pm 11.2$ years,
$1.58 \pm 0.08 \mathrm{~m}, 70.7 \pm 9.4 \mathrm{~kg}$ and $\left.\mathrm{BMI}: 28.6 \pm 3.7 \mathrm{~kg} / \mathrm{m}^{2}\right)$. Six patients from the maneuvers group declined to participate in the study for the following reasons: 2 subjects did not meet the inclusion criteria; and 4 abandoned treatment (Figure 1).

All subjects who participated in the study met the following inclusion criteria: 1 ) have a proven diagnosis (clinical and imaging examination) of COPD; and 2) do not present any neurological, cardiovascular or musculoskeletal problems; in addition to loss of cognitive ability, which would have made it impossible to carry out the evaluation and/or the treatment program. For the sample calculation, G*Power 3.1.0 software was used and the procedures followed the recommendations of Beck ${ }^{(21)}$. A power of 0.95 was adopted a priori considering a significance level of $5 \%$ and an effect size of 0.8 , therefore a total ' $n$ ' of 23 subjects was calculated; however, due to sample loss the calculation was scaled to a power of 0.8 , a significance level of $5 \%$, and an effect size of 0.75 , so that a total ' $n$ ' of 16 subjects was recalculated. This analysis was performed to reduce the probability of type II error and to determine the minimum number of individuals required for this investigation. Thus, the sample size was sufficient to provide $80 \%$ statistical power. All patients who agreed to participate were instructed on the risks and benefits of the study and signed the clear and Informed Consent Form, as established in Resolution 466/12 of the National Health Council (CNS), after its approval by the Ethics Committee in Research of the Health Sciences Center of the Federal University of Paraíba (CEP/CCS/UFPB), under protocol 0120/2014 and CAAE: 30264914.0.0000.5188.

\section{Procedures}

QOL was initially assessed by the Saint George Hospital Respiratory Disease (SGHRQ) self-administered questionnaire, validated and translated into Portuguese by Sousa et al. ${ }^{(22)}$,

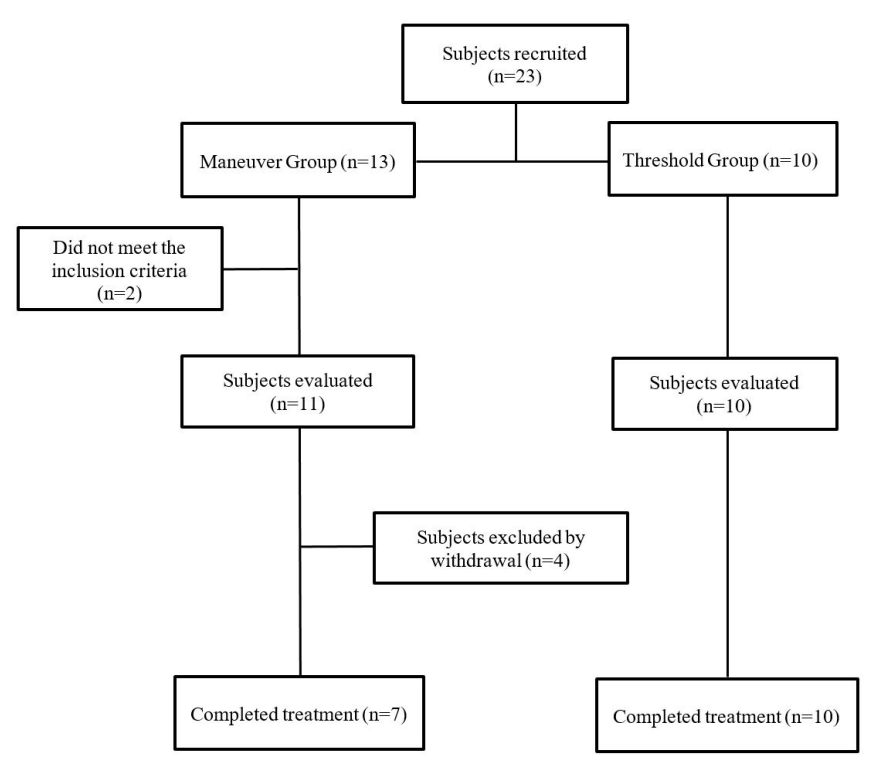

Figure 1. Sample Flow Diagram 
which allows comparing health status among populations of patients and quantify changes in health after therapy. It is divided into three domains (symptoms, activities and psychosocial impacts) for which the respiratory disease inflicts the individual, having a maximum score for each domain where the sum of these results in a score of 0 to $100 \%$, and the higher the percentage, the worse the quality of life is.

Spirometry was performed using a digital pneumonograph (Pneumotach Datalink, France) in a room with a temperature of approximately $20^{\circ} \mathrm{C}^{(23)}$, in which the patients rested for 5 to 10 minutes before the test. They were then instructed to remain in the seated position, using the nasal clip and with their head held in a neutral position (Figure 2B), so as not to change the initial forced expiratory flows by varying the tracheal stiffness and without using bronchodilators ${ }^{(22)}$. In order to measure VC, the patient had an inspiration until total lung capacity (TLC) and expired without interruption until the residual volume (RV) was reached. Then the patient was also asked to expire as fast and intensely as possible after an inspiration to the TLC in order to verify FVC. The test consisted of 3 consecutive repetitions for each maneuver, with an interval of 1 minute between them, and the VC was validated when the difference between at least two maneuvers was less than $0.10 \mathrm{l}$, and the maneuver was repeated if this difference was not obtained. The two largest values should differ less than 0.15 I for validating $\mathrm{FVC}$ and $\mathrm{FEV}_{1}$, with the highest values of VC, FVC and FEV 1 being selected, according to Pereira ${ }^{(12)}$.

In evaluating respiratory muscle strength, a manovacuometer (CriticalMed - Brazil) was used to verify MIP and MEP. To measure MIP, the subject was instructed to exhale to the RV and then inhale up to the TLC, while they were also instructed to inhale up to the TLC and then exhale until the RV in order to gauge the MEP(13). Three attempts were made for each respiratory pressure with a duration of at least 2 seconds and a 1-minute interval between them, with highest value being considered for analysis (Figure 2A).

\section{Intervention}

The treatment protocol was performed at the Clinical School of Physiotherapy of the UFPB and consisted of 30 sessions ( 3 times/week), each lasting 55 minutes for 10 weeks. The training sessions of the "Maneuvers" group consisted of 10 minutes of stretching the muscles of the upper and lower limbs; 15 minutes of upper and lower rib pompage, as well as sternocleidomastoid (SCM) and anterior scalene (AS) muscle pompage; 20 minutes of respiratory maneuvers (thoraco-abdominal re-education - TAR, and expiratory flow

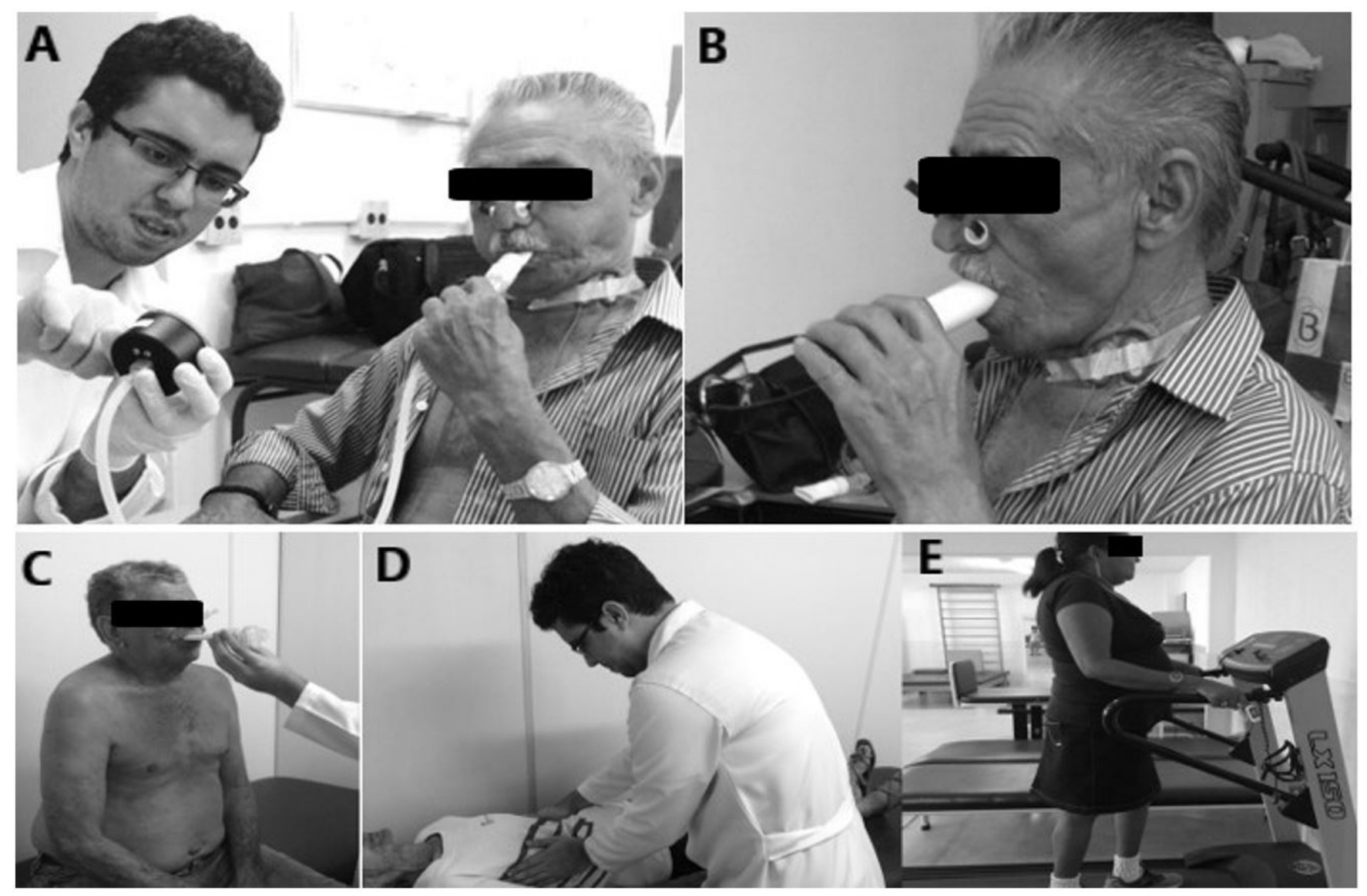

Figure 2. (A) Manovacuometry, (B) spirometry, (C) inspiratory muscle training, (D) expiratory flow acceleration and (E) aerobic training, in patients with COPD. 
acceleration - EFA); functional respiratory re-education by means of diaphragmatic respiration and pursed-lip breathing, ${ }^{(20,24)}$ and aerobic training on the treadmill for 20 minutes with a workload of $70 \%$ maximum heart rate $(H R)\left(H R_{\text {max }}=220\right.$-age $)$, with 2.5 minutes of warmup and 2.5 minutes of cool-down (Figures 2C, D and E). Moreover, the "Threshold" group performed 10 minutes of stretching the muscles of the upper and lower limbs; 15 minutes of upper and lower rib pompage, as well as sternocleidomastoid (SCM) and anterior scalene (AS) muscle pompage; 10 minutes of inspiratory muscle training using the Threshold (Respiron - NCS, Brazil) at 40\% MIP obtained in the first session of each week; and aerobic training on the treadmill for 20 minutes with a workload of $70 \%$ maximum heart rate $\left(\mathrm{HR}_{\max }=220\right.$-age), with 2.5 minutes of warm-up and 2.5 minutes of cool-down (Figure 2C, D and AND).

\section{Data analysis}

The Statistical Package for the Social Sciences (SPSS - 20.0, Armonk, USA)) software program was used for the statistical procedures. First, normality tests (Shapiro-Wilk) were performed, followed by Student's t-test (paired) and Wilcoxon test for pre and post-intervention comparisons of SGRQ domains and total score, VC, FVC, FEV ${ }_{1}$, MIP and MEP, and Student's t-test (independent) and Mann-Whitney in the intergroup comparison, considering a significance level of $5 \%$ for all analyzes. In comparing the anthropometric variables, the intra-class correlation test (ICC) was used according to the following classification: null $=0.0$; weak $=0.01$ to 0.3 ; regular $=0.31$ to 0.6 ; strong $=0.61$ to 0.9 ; very strong $=0.91$ to $0.99 ;$ and full $=1.0 .^{(25)}$

\section{RESULTS}

The ICC showed very strong ( $r=0.91$ to 0.99 ) and significant $(P<0.001)$ correlations between the groups (Maneuvers $X$ Threshold) for the anthropometric variables: Age $(r=0.951$, $P<0.001)$; Height $(r=0.958, P<0.001)$ and BMI $(r=0.902, P$ $<0.006)$; and strong ( $r=0.61$ to 0.9$)$ for Body Mass ( $r=0.758$, $\mathrm{P}<0.048)$, according to Araújo et al. ${ }^{(25)}$. According to Table 1, there was a significant difference for both the "Maneuvers" group (Symptoms: $\mathrm{P}=0.003$; Activities: $\mathrm{P}=0.021$; Psychosocial Impact: $\mathrm{P}=0.018$; Total: $\mathrm{P}=0.002$ ) and for the "Threshold" group (Symptoms: $P=0.017$; Activities: $P=0.012$; Psychosocial Impact: $P=0.003$; and Total: $P=0.001$ ) in comparing the SGRQ pre and post intervention values in the 3 domains and in the total score. As can be seen in Table 2, there was no significant difference $(P>0.05)$ in the comparison between the intergroup SGRQ domain values (Maneuvers $x$ Threshold) in both the pre- and post-intervention physiotherapy.

For spirometry (VC, FVC, and $\mathrm{FEV}_{1}$ ), there was no significant difference in any of the analyzed variables for the "Maneuvers" group (VC: $\mathrm{P}=0.099$; FVC: $\mathrm{P}=0.871$; and $F_{1} \mathrm{~V}_{1}: \mathrm{P}=0.288$ ), or for the "Threshold" group (FVC: $P=0.386, V C: P=0.455$, and $\left.\mathrm{FEV}_{1}: \mathrm{P}=0.117\right)$. However, there was a significant difference in relation to manovacuometry (MIP and MEP) in the comparison of pre and post-intervention values, both in the "Maneuvers" group (MIP: $\mathrm{P}=0.028, \mathrm{MEP}: \mathrm{P}=0.046$ ) and in the "Threshold" group (MIP: $P=0.028$, MEP: $P=0.028$ ), as can be seen in Table 3. There were no significant differences $(P>0.05)$ in the intergroup comparison (Maneuvers $x$ Threshold) either pre- or post-intervention (Table 4) in all the analyzed variables: spirometry (VC, FVC and $\mathrm{FEV}_{1}$ ) and manovacuometry (MIP and MEP).

Table 1. Comparison of the intra-group Saint George Respiratory Questionnaire domain values (pre X post-intervention physiotherapy).

\begin{tabular}{|c|c|c|c|c|c|c|}
\hline \multirow{2}{*}{ Domains } & \multicolumn{3}{|c|}{ Maneuver } & \multicolumn{3}{|c|}{ Threshold } \\
\hline & Pre & Post & P Valor & Pre & Post & P Valor \\
\hline Symptoms & $67.2 \pm 9.1$ & $30.4 \pm 18.9$ & 0.0030 & $56.6 \pm 18.1$ & $31.7 \pm 29.8$ & $0.017+$ \\
\hline Activities & $63.2 \pm 31.9$ & $40.1 \pm 19.4$ & 0.0210 & $76.7 \pm 12.6$ & $58.9 \pm 21.9$ & 0.0120 \\
\hline Impact & $51.0 \pm 29.1$ & $28.4 \pm 23.8$ & $0.018+$ & $50.4 \pm 17.3$ & $36.0 \pm 20.9$ & 0.0030 \\
\hline Total & $57.5 \pm 24.8$ & $32.3 \pm 18.1$ & 0.0020 & $59.4 \pm 14.9$ & $42.3 \pm 19.8$ & 0.0010 \\
\hline
\end{tabular}

Note: $\diamond=$ Student $t$ test (paired); $\dagger=$ Wilcoxon test

Table 2. Comparison of intergroup Saint George Respiratory Questionnaire domain values (Maneuvers vs. Threshold) pre- and post physiotherapeutic intervention.

\begin{tabular}{|c|c|c|c|c|c|c|}
\hline \multirow{2}{*}{ Domains } & \multicolumn{3}{|c|}{ Maneuver } & \multicolumn{3}{|c|}{ Threshold } \\
\hline & Pre & Post & P Valor & Pre & Post & P Valor \\
\hline Symptoms & $67.2 \pm 9.1$ & $56.6 \pm 18.1$ & 0.1740 & $30.4 \pm 18.9$ & $31.7 \pm 29.8$ & $0.740+$ \\
\hline Activities & $63.2 \pm 31.9$ & $76.7 \pm 12.6$ & 0.2400 & $40.1 \pm 19.4$ & $58.9 \pm 21.9$ & 0.0890 \\
\hline Impact & $51.0 \pm 29.1$ & $50.4 \pm 17.3$ & $0.954 \diamond$ & $28.4 \pm 23.8$ & $36.0 \pm 20.9$ & $0.270 \dagger$ \\
\hline Total & $57.5 \pm 24.8$ & $59.4 \pm 14.9$ & 0.8430 & $32.3 \pm 18.1$ & $42.3 \pm 19.8$ & 0.3080 \\
\hline
\end{tabular}

Note: $\diamond=$ Student $t$ test (nonpaired) $\dagger=$ Mann-Whitney test. 
Table 3. Comparison of intragroup respiratory variables (spirometry and manovacuometry) pre- and post- physiotherapeutic intervention.

\begin{tabular}{|c|c|c|c|c|c|c|}
\hline \multirow{2}{*}{ Variables } & \multicolumn{3}{|c|}{ Manuever } & \multicolumn{3}{|c|}{ Threshold } \\
\hline & Pre & Post & P Valor & Pre & Post & P Valor \\
\hline VC & $2.21 \pm 0.93$ & $2.32 \pm 0.93$ & 0.0990 & $1.67 \pm 0.70$ & $1.81 \pm 0.79$ & $0.386^{+}$ \\
\hline FVC & $1.70 \pm 0.71$ & $1.72 \pm 0.69$ & 0.8710 & $1.34 \pm 0.63$ & $1.39 \pm 0.66$ & $0.455 \diamond$ \\
\hline $\mathrm{FEV}_{1}$ & $1.25 \pm 0.53$ & $1.36 \pm 0.68$ & 0.2880 & $0.94 \pm 0.50$ & $1.04 \pm 0.62$ & $0.117 \diamond$ \\
\hline MIP & $66.3 \pm 32.4$ & $103.4 \pm 32.7$ & $0.028^{+}$ & $80.0 \pm 36.2$ & $97.2 \pm 26.3$ & $0.028+$ \\
\hline MEP & $93.4 \pm 21.4$ & $113.1 \pm 8.9$ & $0.046{ }^{\dagger}$ & $87.6 \pm 31.1$ & $105.4 \pm 24.0$ & $0.028^{+}$ \\
\hline
\end{tabular}

Note: $\mathrm{VC}=$ Vital Capacity; $F \mathrm{FC}=$ Forced Vital Capacity; $\mathrm{FEV}_{1}=$ Forced Expiratory Volume in the first second; $\mathrm{MIP}=$ Inspiratory pressure maximum; MEP $=$ Expiratory pressure maximum. Note: $\diamond=$ Student $t$ test; $\dagger=$ Wilcoxon test.

Table 4. Comparison of intergroup respiratory variables (spirometry and manovacuometry) pre- and post- physiotherapeutic intervention.

\begin{tabular}{|c|c|c|c|c|c|c|}
\hline \multirow{2}{*}{ Variables } & \multicolumn{3}{|c|}{ Pre-Intervention } & \multicolumn{3}{|c|}{ Post-Intervention } \\
\hline & Maneuver & Threshold & P Valor & Maneuver & Threshold & P Valor \\
\hline VC & $2.21 \pm 0.93$ & $1.67 \pm 0.70$ & $0.230+$ & $2.32 \pm 0.93$ & $1.81 \pm 0.79$ & 0.2390 \\
\hline FVC & $1.70 \pm 0.71$ & $1.34 \pm 0.63$ & 0.2910 & $1.72 \pm 0.69$ & $1.39 \pm 0.66$ & 0.3340 \\
\hline $\mathrm{FEV}_{1}$ & $1.25 \pm 0.53$ & $0.94 \pm 0.50$ & 0.2470 & $1.36 \pm 0.68$ & $1.04 \pm 0.62$ & 0.3280 \\
\hline MIP & $66.3 \pm 32.4$ & $80.0 \pm 36.2$ & 0.4350 & $103.4 \pm 32.7$ & $97.2 \pm 26.3$ & $0.669+$ \\
\hline MEP & $93.4 \pm 21.4$ & $87.6 \pm 31.1$ & 0.6740 & $113.1 \pm 8.9$ & $105.4 \pm 24.0$ & $0.887+$ \\
\hline
\end{tabular}

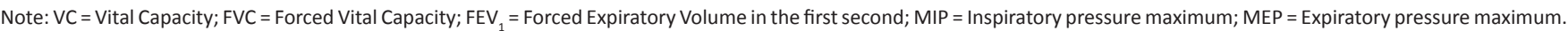
Note: $\diamond=$ Student $\mathrm{t}$ test (non paried); $\dagger=$ Mann-Whitney test.

\section{DISCUSSION}

The main findings in the present study generally showed an exponential improvement in QOL quantified in all SGHRQ domains and manovacuometry data (MIP and MEP) of patients with COPD in the 2 analyzed protocols (Maneuvers and Threshold). The post-intervention SGHRQ values in all domains point to an improvement in the QOL of these subjects, thus suggesting that both protocols have positively provided recovery in these patients, since according to Teixeira et al. ${ }^{(26)}$, estimating the QOL enables quantifying the degree of influence the disease has on the lives of these patients, since this is a way to evaluate their response to treatment. The results of the present study corroborate those found by Paulin et al. ${ }^{(18)}$, who underwent a 8-week pulmonary rehabilitation program; and Teixeira et al. ${ }^{(26)}$ who submitted patients to upper and lower limb strengthening exercises with aerobic training on a treadmill for 12 weeks, where both studies showed a reduction in the values of the 3 domains and in the total score of the SGRQ post-physiotherapeutic intervention. In this sense, Furlanetto et al. ${ }^{(27)}$ compared 104 active and inactive subjects with COPD using a biaxial accelerometer combined with physiological sensors SenserWear Armband - SWA (BodyMedia Inc., Pittsburgh, PA), who observed that physically active subjects had better aerobic capacity and pulmonary function compared to inactive subjects. Regarding the spirometric evaluation, it was verified that there was no improvement in the pulmonary function of VC, FVC and FEV ${ }_{1}$ variables, which shows that there was no change in the airway obstruction level. This corroborates the study by O'Donnell et al. ${ }^{(28)}$, who also did not find significant improvements in spirometry after intervention after analyzing 20 COPD patients who underwent a physical therapy intervention protocol consisting of physical and respiratory exercise sessions for 6 weeks. Likewise, Jamami et al. ${ }^{(29)}$ also did not find a significant difference in pulmonary function in analyzing 22 subjects who underwent physical activities, inspiratory muscle training and respiratory re-education for 6 weeks (2 times/week).

A possible explanation for the fact that spirometry data remained unchanged was reported by Tiep ${ }^{(30)}$ when describing that pulmonary function tests, especially spirometry, describe the current state of the physiological dysfunction, but it is not able to define the benefits of the rehabilitation program when compared to the well-being referred by the patient. Along these lines, Lopes et al. ${ }^{(31)}$ affirm that repeating spirometry in less than a 1-year interval in stable patients is not useful for comparing post-intervention effects; however, this evaluation should be performed if there is significant worsening of symptoms or some complication in these patients. This fact is confirmed in the study by Paulin et al. ${ }^{(18)}$ and Rodrigues et al. ${ }^{(32)}$, in which they affirm that rehabilitation programs did not show changes in pulmonary function after aerobic physical conditioning, but in the secondary damage from COPD.

Regarding manovacuometry, the results showed that there was a significant improvement of MEP and MIP. This corroborates the study by Kunikoshita et al. ${ }^{(20)}$, who observed a significant increase in MIP in 25 patients with 
COPD after 6 weeks of aerobic training associated with strengthening the inspiratory musculature; and that of Trevisan et al. ${ }^{(33)}$ who affirmed that respiratory muscle training provided improvement in the strength of these muscles and an increase in MIP and MEP with 19 subjects affected by COPD who had undergone 8 weeks of inspiratory muscle strengthening as well as abdominal and quadriceps muscle strengthening exercises, despite not having used aerobic training as in the present study. This is confirmed by Ramírez-Sarmiento et al. ${ }^{(34)}$ in performing a study of 14 COPD patients who underwent inspiratory muscle training or simulated training with no pressure load for 5 weeks ( 30 minutes; 5 days a week), showing that respiratory muscle training improved inspiratory muscle strength and endurance, and they observed adaptive changes in the proportion of type I fibers and type II muscle fibers in subjects submitted to inspiratory muscle training. Regarding MEP, the present study corroborates that of Di Lorenzo et al. ${ }^{(35)}$, which showed that the increase in MEP is due to the fact that the mechanical efficiency of the expiratory muscles is better, since an increase in the inspiratory force provides better performance of these muscles.

A limitation of this study is the low number of subjects due to the difficulty of recruiting them in the study, since these patients rarely seek and/or are referred for specific physiotherapeutic care, making it difficult to participate in the research, thus constituting a factor that may have influenced the results presented herein. There is still the fact that the protocol consists of 30 sessions, 3 times a week, which demands availability and transportation/commuting costs of these patients.

\section{CONCLUSIONS}

The results of the present study showed that the proposed physiotherapeutic protocols promoted improvement in QOL and MIP and MEP muscle strength in all COPD patients, regardless of the group (Maneuvers or Threshold) to which they were allocated, behaving in a similar way in all analyzed variables, and thereby largely confirming the hypothesis of this study. Despite the low sample size, the exponential improvement in QOL, the gain in MIP and MEP, and the low cost of the proposed physiotherapeutic interventions all lead to suggest implementing these protocols in public health services in order to attend patients with COPD.

\section{Acknowledgements}

To all patients who voluntarily participated in this study.

\section{AUTHOR'S CONTRIBUTIONS}

Moura DM, Moura SML, Gonçalves AF, Silva MAS: Data collection and preparation of the manuscript; Winkeler GFP: Revision of the manuscript; Maciel SS and Martins CML: Revision of the manuscript; Santos HH: Statistical treatment, preparation and revision of the manuscript.

\section{CONFLICTS OF INTEREST}

The authors declare that they have no competing interests.

\section{AUTHOR DETAILS}

${ }^{1}$ Curso de Fisioterapia da Universidade Federal da Paraíba/UFPB, João Pessoa, Paraíba, Brasil.

2 Departamento de Promoção e Saúde da Universidade Federal da Paraíba UFPB, João Pessoa, Paraíba, Brasil.

\section{REFERENCES}

1. Facco CR, Soares JC, Mota CB, Trevisan ME. Efeitos de um teste incremental de caminhada na marcha de indivíduos com Doença Pulmonar Obstrutiva Crônica. Fisioter e Pesq. 2014; 21(1):47-52.

2. Farias CC, Resqueti V, Dias FAL, Borghi-Silva A, Arena R, Fregonezi GAF. Costs and benefits of pulmonary rehabilitation in Chronic Obstructive Pulmonary Disease: a randomized controlled trial. Braz J Phys Ther. 2014; 18(2):165-73.

3. Sociedade Brasileira de Pneumologia e Tisiologia. Brasília: DPOC e Saúde Pública - Atendendo as necessidades dos pacientes. Available from: http://www.sbpt.org.br/downloads/arquivos/COM_DPOC/Relatorio_ final_DPOC_Saude_Publica_2012_SBPT

4. Casanova C, Cote C, Torres JP, Aguirre-Jaime A, Marin JM, Pinto-Plata $\mathrm{V}$, et al. Inspiratory-to-total lung capacity ratio predicts mortality in patients with chronic obstructive pulmonar disease. Am J Resp Critical Care Med. 2005;171(11):591-7.

5. Dourado VZ, Tanni SE, Faganello MM, Sanchez FF, Godoy I. Manifestações sistêmicas na doença pulmonar obstrutiva crônica. J Bras Pneumol. 2006; 32(2):161-71.

6. Vestbo J, Hurd SS, Agustí AG, Jones PW, Vogelmeier C, Anzueto A, Barnes PJ, Fabbri LM, Martinez FJ, Nishimura M, Stockley RA, Sin DD, RodriguezRoisin R. Global strategy for the diagnosis, management, and prevention of chronic obstructive pulmonary disease: GOLD executive summary. Am J Respir Crit Care Med. 2013 Feb 15;187(4):347-65.

7. Marino DM, Marrara KT, Arcuri JF, Candolo C, Jamami M, Di Lorenzo VAP. Determination of exacerbation predictors in patients with COPD in physical therapy: a longitudinal study. Braz J Phys Ther. 2014;18(2):127-36.

8. Ottenheijm CAC, Heunks LMA, Dekhuijzen RPN. Diaphragm adaptations in patients with COPD. Respir Res. 2008; 9(1):9-12.

9. Etemadinezhad $S$, Alizadeh A. Valores de referência para espirometria em adultos saudáveis na província de Mazandaran, Irã. J Bras Pneumol. 2011; 37(5):615-20.

10. Barreto SSM. Volumes pulmonares. J Pneumol. 2002; 28(3):83-94.

11. Pereira CAC. Teste de função pulmonar. Brasília: Sociedade Brasileira de Pneumologia e Tisiologia, 2001.

12. Pereira CAC. Espirometria. J Pneumol. 2002; 28(Supl 3):S1-82.

13. Almeida IP, Bertucci NR, Lima VP. Variações da pressão inspiratória máxima e pressão expiratória máxima a partir da capacidade residual funcional ou da capacidade pulmonar total e volume residual em indivíduos normais. Rev. O Mundo da Saúde. 2008;32(2):176-82.

14. Abreu LC, Pereira VX, Valenti VE, Panzarin SSA, Moura Filho OF. Uma visão da prática da fisioterapia respiratória: ausência de evidência não é evidência de ausência. Arq Med ABC. 2007; 32(2):S76-8.

15. Britto MCA, Duarte MCMB, Silvestre SMMC. Fisioterapia respiratória no empiema pleural: Revisão sistemática da literatura. J Bras Pneumol. 2005; 31(6):551-4.

16. Gastaldi AC, Magalhães CMB, Baraúna MA, Silva EMC, Souza HCD. Benefícios da cinesioterapia respiratória no pós-operatório de colecistectomia laparoscópica. Rev Bras Fisioter. 2008; 12(2):100-6.

17. Silva KM, Bromerschenckel AIM. Fisioterapia respiratória nas doenças pulmonares obstrutivas crônicas. Rev HUPE. 2013; 12(2):94-100 
18. Paulin E, Brunetto AF, Carvalho CRF. Efeitos de programa de exercícios físicos direcionado ao aumento da mobilidade torácica em pacientes portadores de doença pulmonar obstrutiva crônica. J Pneumol. 2003; 29(1):287-94.

19. Dourado VZ, Godoy, I. Recondicionamento muscular na DPOC: principais intervenções e novas tendências. Rev Bras Med Esporte. 2004; 10(4):331-4

20. Kunikoshita LN, Silva YP, Silva TLP, Costa D, Jamami M. Efeitos de três programas de fisioterapia respiratória (PFR) em portadores de DPOC. Rev Bras Fisioter. 2006; 10(4):449-55.

21. Beck TW. The importance of a priori sample size estimation in strength and conditioning research. J Strength Cond Res. 2013;27(8):2323-37.

22. Sousa TC, Jardim JR, Jones P. Validação do questionário do Hospital Saint George na doença respiratória em pacientes portadores de DPOC no Brasil. J Pneumol. 2000; 26(3):119-28.

23. Wild LB, Dias AS, Fischer GB, Rech DR. Avaliação da função pulmonar em crianças e adolescentes asmáticos: comparação entre a microespirometria e a espirometria convencional. J Bras Pneumol. 2005; 31(2):97-102.

24. Langer D, Probst VS, Pitta F, Burtin C, Wendriks E, Schans CPVD, et al. Guia para a prática clínica: fisioterapia em pacientes com Doença Pulmonar Obstrutiva Crônica (DPOC). Rev Bras Fisioter. 2009; 13(3):183-204.

25. Araújo AGF, Barbosa GM, Freire RA, Andrade PR, Ferreira JJA, Santos HH. Fidedignidade das medidas inter e intra-testes com goniômetro universal e artrômetro podálico da amplitude ativa de eversão e inversão do tornozelo. Fisioter Pesq. 2014; 21(4):339-45.

26. Teixeira ALS, Braz Junior, DS, Andrade AD, Marinho, PEM. Diferença mínima clinicamente importante da qualidade de vida de pacientes com Doença Pulmonar Obstrutiva Crônica submetidos a um programa de reabilitação pulmonar. Rev Bras Ativ Fis Saúde. 2014; 19(5):559-60.

27. Furlanetto KC, Pinto IFS, Sant'Anna T, Hernandes NA, Pitta F. Profile of patients with chronic obstructive pulmonary disease classified as physically active and inactive according to different thresholds of physical activy in daily life. Braz J Phys Ther. 2016; 20(6):517-24.
28. O’Donnell DE, McGuire M, Samis L, Webb KA. General exercise training improves ventilatory and peripheral muscle strength and endurance in chronic airflow limitation. Am J Respir Crit Care Med. 1998; 157(5):148997.

29. Jamami M, Pires VA, Oishi J, Costa D. Efeitos da intervenção fisioterápica na reabilitação pulmonar de pacientes com doença pulmonar obstrutiva crônica (DPOC). Rev Fisioter Univ São Paulo. 1999; 6(2);140-53

30. Tiep BL. Disease management of COPD with pulmonary rehabilitation. Chest. 1997; 112(6):1630-56

31. Lopes AJ, Faria AC, Bártholo TP. Definições funcionais de asma e doença pulmonar obstrutiva crônica. Rev HUPE. 2013; 12(2):41-53.

32. Rodrigues SL, Viegas CAA, Lima T. Efetividade da reabilitação pulmonar como tratamento coadjuvante da doença pulmonar obstrutiva crônica. J Pneumol. 2002; 28(2):65-70.

33. Trevisan ME, Porto AS, Pinheiro TM. Influência do treinamento da musculatura respiratória e de membros inferiores no desempenho funcional de indivíduos com DPOC. Fisioter e Pesq. 2010; 17(3):209-13.

34. Ramírez-Sarmiento A, Orozco-Levi M, Guell R, Barreiro E, Hernandez $\mathrm{N}$, Mota S, et al. Inspiratory muscle training in patients with Chronic Obstructive Pulmonary Disease: structural adaptation and physiologic outcomes. Am J Respir Crit Care Med. 2002; 166(11):1491-7.

35. Di Lorenzo VAP, Silva AB, Sampaio LMM, Jamami M, Oishi J, Costa D. Efeitos de treinamento físico e muscular respiratório em pacientes com Doença Pulmonar Obstrutiva Crônica (DPOC) grave submetidos a BiPAP. Rev Bras Fisioter. 2003; 7(1):69-76. 